\title{
Upper water structure and mixed layer depth in tropical waters: The SEATS station in the northern South China Sea
}

\author{
Jen-Hua Tai ${ }^{1, *}$, George T. F. Wong ${ }^{1,2}$, and Xiaoju Pan ${ }^{3}$ \\ ${ }^{1}$ Research Center for Environmental Changes, Academia Sinica, Taipei City, Taiwan \\ ${ }^{2}$ Department of Ocean, Earth and Atmospheric Sciences, Old Dominion University, Norfolk, VA, USA \\ ${ }^{3}$ Key Laboratory of Marine Chemistry Theory and Technology, Ministry of Education, Ocean University of China, Qingdao,
} China

\section{Article history:}

Received 6 October 2016

Revised 7 January 2017

Accepted 9 January 2017

Keywords:

Climatology, Mixed layer depth, South China Sea, Diurnal variations, Seasonal variations

Citation:

Tai, J.-H., G. T. F. Wong, and X. Pan, 2017: Upper water structure and mixed layer depth in tropical waters: The SEATS station in the northern South China Sea. Terr. Atmos. Ocean. Sci., 28, 1019-1032, doi: 10.3319/TAO.2017.01.09.01

\begin{abstract}
The variability of the upper water hydrographic structure, the efficacy of the different schemes for estimating the mixed layer depth (MLD), the inter-comparability estimation of the MLDs and diurnal and intra-annual MLD climatology in the tropical waters in the northern South China Sea were accessed in 702 depth-profiles of potential temperature $(\theta)$ and salinity collected in 64 cruises between 17.5 and $18.5^{\circ} \mathrm{N}$ and 115.3 and $116.3^{\circ} \mathrm{E}$ from 1997 to 2013 . The hydrographic structure may be subdivided into three principal types: the classical type, with quasi-isopycnal surface mixed layer followed by an abrupt increase in the depth-gradient in $\theta$ and potential density $\left(\sigma_{\theta}\right)$ to mark the MLD; the stepwise type, with one or more small stepwise decreases in $\theta$ and/or increases in $\sigma_{\theta}$ in the mixed layer; and the graded type, with a general decrease in $\theta$ and increases in $\sigma_{\theta}$ with depth into the main pycnocline without a clear break to mark the MLD. These three types of upper waters were found in 75, 10 , and $15 \%$ of the cruises. Out of the 10 schemes for estimating the MLD, only the fixed temperature difference method of 0.5 and $0.8^{\circ} \mathrm{C}$ from the $10-\mathrm{m}$ temperature yielded consistent results, with root mean square error and mean absolute percentage difference of $2 \mathrm{~m}$ and $2 \%$. MLD varied diurnally with an average standard deviation of $4 \mathrm{~m}$ from the mean. The monthly average MLD reached a maximum of $80 \mathrm{~m}$ in December/January and dropped to a minimum of $25 \mathrm{~m}$ in May.
\end{abstract}

\section{INTRODUCTION}

The mixed layer, the thin, nearly isopycnic surface layer, is a distinct and important sub-environment in the world's oceans. It separates the atmosphere from the deep ocean, and thus, modulates, if not regulates to a significant extent, the exchange of energy, momentum and matter between the two (Lukas and Lindstrom 1991; Brainerd and Gregg 1995; Dong et al. 2008). For example, the deep ocean is a vast geochemical reservoir containing an immense quantity of carbon dioxide, more than an order of magnitude higher than that in the atmosphere and the mixed layer combined. This carbon dioxide cannot escape readily to the atmosphere (Maier-Reimer and Hasselmann 1987; Sabine and Tanhua 2010). Yet, the effective sequestration of anthropogenic atmospheric carbon dioxide in the deep ocean

\footnotetext{
* Corresponding author

E-mail:jhtai@gate.sinica.edu.tw
}

is limited by the amount of carbon dioxide that can bypass the mixed layer and reach the deep ocean, as much of it stays in the mixed layer where it may be released back into the atmosphere (Ducklow et al. 2001). The environmental conditions in the mixed layer are also starkly different from those in the deep ocean. The mixed layer is well lit, warm, depleted in nutrients and high in the concentration of particles. It is biogeochemically much more dynamic and diverse than the deep ocean and it is the site where photosynthesis is possible (Ducklow et al. 2001).

The mixed layer thickness, or the mixed layer depth (MLD), is a primary mixed layer characteristic that determines its reservoir size and its effectiveness in isolating the deep ocean from the atmosphere, and it is frequently a necessary input parameter in geochemical modeling exercises. Many criteria have been used for defining the MLD. The more widely used methods basically fall under four 
general categories: (1) fixed temperature difference (FTD) methods - the depth at which the potential temperature, $\theta$, has decreased by a prescribed amount relative to a reference depth, preferably the sea surface; (2) fixed density difference (FDD) methods - the depth at which the potential density, $\sigma_{\theta}$, has increased by a prescribed amount relative to a reference depth, again preferably the sea surface; (3) fixed temperature gradient (FTG) methods - the depth at which the gradient in $\theta$ with depth $z, \delta \theta / \delta z$, has increased to a prescribed value; and (4) fixed density gradient (FDG) method - the depth at which the gradient in $\sigma_{\theta}$ with depth, $\delta \sigma_{\theta} / \delta z$, has risen to a prescribed value. The prescribed values that have been used varied, for example, a drop in $\theta$ of 0.2 (Thompson 1976), 0.5 (Price et al. 1986; Kelly and Qiu 1995; Obata et al. 1996; Monterey and Levitus 1997), 0.8 (Kara et al. 2000; Qu et al. 2007) or even $1.0^{\circ} \mathrm{C}$ (Lamb 1984; Wagner 1996), an increase in $\sigma_{\theta}$ of 0.125 or $0.13 \sigma_{\theta}$ unit (Miller 1976; Levitus 1982; Spall 1991; Huang and Russell 1994), an increase in $-\delta \theta / \delta z$ to $0.05^{\circ} \mathrm{C} \mathrm{m}^{-1}$ (Qu 2001; Hao et al. 2012) and an increase in $\delta \sigma_{\theta} / \delta z$ to 0.01 (Lukas and Lindstrom 1991), 0.05 (Tseng et al. 2007) or $0.1 \sigma_{\theta}$ unit $\mathrm{m}^{-1}$ (Tseng et al. 2005; Wong et al. 2007a, b) in the FTD, FDD, FTG, and FDG methods, respectively. The reference depths used include the sea surface (Miller 1976; Thompson 1976; Levitus 1982; Lamb 1984; Price et al. 1986; Spall 1991; Huang and Russell 1994; Kelly and Qiu 1995; Obata et al. 1996; Wagner 1996; Monterey and Levitus 1997) and 10 $\mathrm{m}$ below the sea surface (Kara et al. 2000; Qu et al. 2007). Nevertheless, in all of these schemes, a certain amount of subjectivity exists, or even arbitrariness, involved in the selection of criterion for defining the MLD. In some cases, the choices may have been dictated by data availability such as the lack of sea surface values. Each of these approaches has its merits and weaknesses and may not be universally efficacious. For example, while the FTD methods are appealing because the needed data are more widely available as even bathythermographic records will be sufficient for the purpose, the nearly isopycnic mixed layer is not invariably isothermal and isohaline. In cases when there is a salinity structure in the mixed layer, a barrier layer may exist and the FTD method may not then be suitable for estimating the MLD (Miller 1976; Lukas and Lindstrom 1991; Sprintall and Tomczak 1992; Montégut et al. 2004). The FDD method reflects the formation physics of the mixed layer more closely but the salinity data, which are required for estimating density, are not as readily available as the temperature data. The FDG method circumvents the need of a reference depth but it again requires salinity data and it also involves additional data processing. Other algorithms for estimating the MLD have been proposed (Lewis et al. 1990) but they are not yet widely used. Among them, the maximum density gradient (MDG) method (Zawada et al. 2005), in which MLD is defined as the depth at which $\delta \sigma_{\theta} / \delta z$ reaches the maximum value, seems especially interesting since it cir- cumvents the need for specifying a reference depth but also a prescribed threshold value. Thus, discussions on defining, characterizing and modeling the MLD are still ongoing and there is not yet a universally accepted practice for determining the MLD.

Vertical mixing induced by advective overturn resulted from heat exchange at the sea-surface and by wind action are two primary mechanisms that control the MLD. In the tropical ocean, both processes can be less effective. As a result, MLD generally tends to decrease with decreasing latitude, and, the seasonal variations in MLD in the tropical waters tend to be smaller (Monterey and Levitus 1997; Montégut et al. 2004). As a part of several studies for diverse purposes, the MLD in the tropical northern South China Sea (SCS) has been estimated by various investigators using a variety of different methods: a FTD method with a drop in $\theta$ of $0.8^{\circ} \mathrm{C}$ relative to that at $10 \mathrm{~m}(\mathrm{Qu}$ et al. 2007); a FTG method at a temperature gradient of $0.05^{\circ} \mathrm{C} \mathrm{m}^{-1}(\mathrm{Qu} 2001$; Ge et al. 2003; Hao et al. 2012); a FDG method at density gradients of 0.05 (Tseng et al. 2007) or $0.1 \sigma_{\theta}$ unit $/ \mathrm{m}$ (Tseng et al. 2005, 2009; Wong et al. 2007b). Wong et al. (2007b) reported that, unlike what is expected in tropical waters, the MLD in the northern SCS varies over a relatively wide range seasonally, from $20 \mathrm{~m}$ in the summer to $90 \mathrm{~m}$ in the winter. Nevertheless, the justifications for the choice of method used for estimating the MLD in these studies were not clearly discussed and the inter-comparability among these reported MLDs have not been assessed. In the Southeast Asian Time-series Study (SEATS), repetitive conductivity-temperature-depth (CTD) profiling data in high depth-resolution at a station at around $18.2^{\circ} \mathrm{N}, 115.7^{\circ} \mathrm{E}$ in the tropical northern SCS have been collected over the years since 1999. In addition, other Taiwanese investigators have also collected CTD profiling data through profiling in the vicinity of the SEATS station at other times. These datasets are pooled here in order to examine the variability in the hydrographic structure in the upper water, to assess the relative efficacies of these algorithms for estimating the MLD and the inter-comparability of the estimated values, and to establish in greater detail the MLD climatology in the diurnal and intra-annual time scales in these tropical waters.

\section{DATA AND METHODS}

\subsection{The Study Area - The Southeast Asian Time-Series Study (SEATS) Site}

The SEATS station is located nominally at $18^{\circ} \mathrm{N}, 116^{\circ} \mathrm{E}$ in the northern SCS in $3800 \mathrm{~m}$ of water (Fig. 1). Its exact location has varied between 17.9 and $18.4^{\circ} \mathrm{N}$ and 115.4 and $116.1^{\circ} \mathrm{E}$. Since 2000 its location has been confined at 17.9 $18.4^{\circ} \mathrm{N}$ and $115.4-115.7^{\circ} \mathrm{E}$ (Wong et al. 2007a). The SCS is the largest marginal sea in the tropics. It stretches from about $23^{\circ} \mathrm{N}$ at the southern coast of the Taiwan Island and the Chinese Mainland to $3^{\circ} \mathrm{S}$ at the coasts of Borneo and 
Sumatra in the tropical zone, and from $102^{\circ} \mathrm{E}$ along the east coast of the Malaysian Peninsula to $121^{\circ} \mathrm{E}$ along the western coasts of the Philippine Islands. Its maximum depth can exceed $5000 \mathrm{~m}$. The northern SCS constitutes the northern half of the SCS north of about $13^{\circ} \mathrm{N}$. It is connected to the East China Sea to the north through the shallow Taiwan Strait, with a sill depth of about $40 \mathrm{~m}$, and to the northwestern Pacific to the east through the only deep channel to the SCS, the Luzon Strait, with a sill depth of about $2200 \mathrm{~m}$ (Sprintall et al. 2012). The northern SCS is filled with four principal water masses: the mixed layer water, the saline Tropical Water and the fresher North Pacific Intermediate Water whose cores appear as a salinity-maximum at $100-150 \mathrm{~m}$ and a salinity-minimum at $400-500 \mathrm{~m}$ respectively, and, the highly homogeneous deep water which fills the SCS basin below $2000 \mathrm{~m}$. The MLD in the northern SCS is rather shallow and variable. Most of the year, it is about $20-40 \mathrm{~m}$. In the winter, it can reach as deep as almost $100 \mathrm{~m}$ (Wong et al. 2007b). Thus, in much of the year, the mixed layer water can exchange rather freely with those in the East China Sea and the northwestern Pacific. The remaining three subsurface water masses all originate from the north Pacific and they find their way into the northern SCS through the Luzon Strait (Shaw 1989, 1991; Qu et al. 2000). In the upper water, mixing with the Tropical Water is an important control on the mixed layer water composition (Tseng et al. 2007). During the exchange of water between the Philippine Sea and the SCS through the Luzon Strait, some of the strongest internal waves in the world are generated at the bottom of the mixed layer (Liu et al. 1998; Liu and Hsu 2004; Ramp et al. 2004). These waves propagate primarily westward and cover a large portion of the northern SCS but the SEATS station is located outside of their major propagation pathways (Zhao et al. 2004).

\subsection{Data from the SEATS Station}

The SEATS station has been occupied in mostly seasonal to biannual intervals since 1999. The data obtained between 1999 and 2013 are used in this study. During this period of time, the station was occupied 43 times aboard the R/V Ocean Researcher I, the R/V Ocean Researcher III or the R/V Fishery Researcher I. A listing of the time for each of these station occupations is given in Table 1. During each station occupation, the vertical temperature and salinity distributions were recorded repeatedly with a SeaBird model SBE9/11 conductivity-temperature-depth (CTD) profiling recorder once every 1 to $3 \mathrm{hr}$ over a time period of at least $24 \mathrm{hr}$ whenever the sea-state permitted.

\subsection{Data from the Vicinity of the SEATS Station}

Between 1997 and 2009,21 additional stations were also occupied between 17.5 and $18.5^{\circ} \mathrm{N}$ and 115.3 and $116.3^{\circ} \mathrm{E}$ aboard R/V Ocean Researcher I or R/V Ocean Research III. They covered an area within approximately $0.5^{\circ}$ from the SEATS station. During each occupation of these stations, the temperature and salinity distributions were recorded in a single pass-through with a SeaBird model SBE9/11 CTD profiling recorder. These data were made available to this study by the Ocean Data Bank of the Ministry of Science and Technology, Taiwan (http://www.odb.ntu.edu.tw) that is maintained by the Institute of Oceanography, National Taiwan University. The timings for these station occupations are also listed in Table 1.

\subsection{Estimations of MLD}

The MLDs during the station occupations was

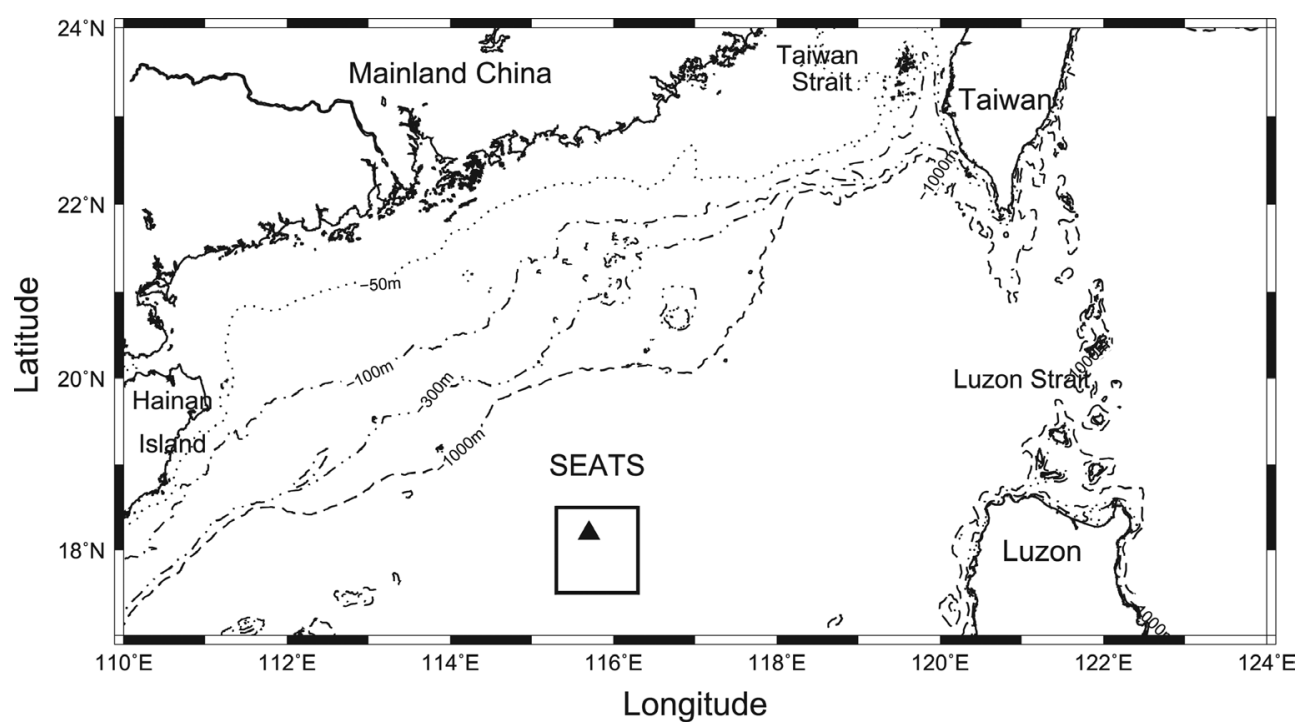

Fig. 1. The study area. The box indicates the area within which the data were used in this study. SEATS - Southeast Asian Time-series Study station. 
Table 1. Station occupation statistics at the SEATS station and its nearby waters.

\begin{tabular}{|c|c|c|c|c|c|c|c|c|c|c|c|c|c|}
\hline Year & January & February & March & April & May & June & July & August & September & October & November & December & Annual total \\
\hline 1997 & 0 & 0 & 0 & $1(0 / 1)$ & 0 & $1(0 / 1)$ & 0 & 0 & 0 & $1(0 / 1)$ & 0 & 0 & $3(0 / 3)$ \\
\hline 1998 & 0 & 0 & 0 & 0 & $1(0 / 1)$ & $1(0 / 1)$ & 0 & 0 & 0 & 0 & 0 & 0 & $2(0 / 2)$ \\
\hline 1999 & 0 & 0 & 0 & $1(0 / 1)$ & 0 & 0 & 0 & $1(0 / 1)$ & $2(1 / 1)$ & 0 & $1(1 / 0)$ & $1(0 / 1)$ & $6(2 / 4)$ \\
\hline 2000 & $1(1 / 0)$ & 0 & $2(1 / 1)$ & 0 & $1(1 / 0)$ & 0 & $2(2 / 0)$ & 0 & 0 & $1(1 / 0)$ & 0 & 0 & $7(6 / 1)$ \\
\hline 2001 & 0 & $1(1 / 0)$ & $1(0 / 1)$ & 0 & 0 & $1(1 / 0)$ & 0 & 0 & 0 & $2(1 / 1)$ & 0 & $1(1 / 0)$ & $6(4 / 2)$ \\
\hline 2002 & 0 & 0 & $2(1 / 1)$ & 0 & 0 & 0 & $1(1 / 0)$ & 0 & $1(1 / 0)$ & $1(1 / 0)$ & $1(1 / 0)$ & 0 & $6(5 / 1)$ \\
\hline 2003 & $1(1 / 0)$ & 0 & $1(1 / 0)$ & 0 & 0 & 0 & $1(0 / 1)$ & $1(1 / 0)$ & 0 & $1(1 / 0)$ & 0 & $1(1 / 0)$ & $6(5 / 1)$ \\
\hline 2004 & 0 & 0 & $1(1 / 0)$ & 0 & $1(1 / 0)$ & $1(0 / 1)$ & 0 & $1(1 / 0)$ & 0 & 0 & $1(1 / 0)$ & 0 & $5(4 / 1)$ \\
\hline 2005 & $1(1 / 0)$ & 0 & $1(1 / 0)$ & 0 & 0 & 0 & $1(1 / 0)$ & 0 & 0 & 0 & $1(1 / 0)$ & $1(1 / 0)$ & $5(5 / 0)$ \\
\hline 2006 & 0 & 0 & 0 & 0 & 0 & $1(0 / 1)$ & $2(1 / 1)$ & $1(0 / 1)$ & 0 & $1(1 / 0)$ & 0 & 0 & $5(2 / 3)$ \\
\hline 2007 & $2(2 / 0)$ & 0 & 0 & 0 & 0 & 0 & $1(1 / 0)$ & 0 & 0 & $1(1 / 0)$ & 0 & 0 & $4(4 / 0)$ \\
\hline 2008 & 0 & 0 & 0 & 0 & $1(0 / 1)$ & 0 & 0 & 0 & 0 & 0 & 0 & $1(0 / 1)$ & $2(0 / 2)$ \\
\hline 2009 & 0 & 0 & 0 & 0 & 0 & 0 & $1(0 / 1)$ & 0 & 0 & 0 & 0 & 0 & $1(0 / 1)$ \\
\hline 2010 & 0 & 0 & 0 & 0 & 0 & 0 & 0 & 0 & 0 & $1(1 / 0)$ & 0 & 0 & $1(1 / 0)$ \\
\hline 2011 & 0 & 0 & 0 & 0 & 0 & 0 & 0 & 0 & 0 & 0 & 0 & $1(1 / 0)$ & $1(1 / 0)$ \\
\hline 2012 & 0 & 0 & 0 & 0 & 0 & 0 & 0 & $1(1 / 0)$ & 0 & 0 & 0 & 0 & $1(1 / 0)$ \\
\hline 2013 & 0 & 0 & 0 & $1(1 / 0)$ & 0 & 0 & 0 & 0 & 0 & $1(1 / 0)$ & 0 & $1(1 / 0)$ & $3(3 / 0)$ \\
\hline \multirow[t]{2}{*}{ Total } & $5(5 / 0)$ & $1(1 / 0)$ & $8(5 / 3)$ & $3(1 / 2)$ & $4(2 / 2)$ & $5(1 / 4)$ & $9(6 / 3)$ & $5(3 / 2)$ & $3(2 / 1)$ & $10(8 / 2)$ & $4(4 / 0)$ & $7(5 / 2)$ & $64(43 / 21)$ \\
\hline & \multicolumn{4}{|c|}{$\begin{array}{l}\text { Northeast monsoon (November - April): } \\
\qquad 28(21 / 7)\end{array}$} & $\begin{array}{c}\text { I } \\
\text { (May): } \\
4(2 / 2)\end{array}$ & \multicolumn{4}{|c|}{$\begin{array}{l}\text { Southwest monsoon (June - September): } \\
\qquad 22(12 / 10)\end{array}$} & $\begin{array}{c}\text { I (Octo- } \\
\text { ber): } 10 \\
(8 / 2)\end{array}$ & \multicolumn{2}{|c|}{$\begin{array}{c}\text { Northeast monsoon } \\
\text { (November - April): } 28 \\
(21 / 7)\end{array}$} & \\
\hline
\end{tabular}

determined from CTD data using ten schemes: namely, $\mathrm{MLD}_{\mathrm{T} 2}, \mathrm{MLD}_{\mathrm{T} 5}, \mathrm{MLD}_{\mathrm{T}}, \mathrm{MLD}_{\mathrm{T} 10}, \mathrm{MLD}_{\sigma}, \mathrm{MLD}_{\theta \mathrm{G}}, \mathrm{MLD}_{\sigma \mathrm{G} 1}$, $\mathrm{MLD}_{\sigma \mathrm{G} 5}, \mathrm{MLD}_{\sigma \mathrm{G} 10}$, and $\mathrm{MLD}_{\mathrm{mdg}}$. These ten schemes may be subdivided into four groups and their definitions are described as follows:

(1) Fixed temperature difference (FTD) schemes (Thompson 1976; Kelly and Qiu 1995; Wagner 1996; Kara et al. 2000): The reference temperature at $10 \mathrm{~m}, \mathrm{~T}_{\text {ref }}$, was determined. The temperatures at successively greater depths were compared to this $\mathrm{T}_{\text {ref }}$ until a difference of 0.2. 0.5, 0.8 , and $1.0^{\circ} \mathrm{C}$ was found. These depths were designated as the $\mathrm{MLD}_{\mathrm{T} 2}, \mathrm{MLD}_{\mathrm{T} 5}, \mathrm{MLD}_{\mathrm{T} 8}$, and $\mathrm{MLD}_{\mathrm{T} 10}$ respectively.

(2) Fixed density difference (FDD) scheme (Levitus 1982; Huang and Russell 1994): The potential densities at increasing depths in the sub-surface were compared to that, $\sigma_{\theta(\mathrm{ref})}$, at $10 \mathrm{~m}$. The depths at which the $\sigma_{\theta}$ had exceeded $\sigma_{\theta(\text { (ref })}$ by $0.125 \sigma_{\theta}$ unit was designated as MLD $_{\sigma}$.

(3) Fixed temperature gradient (FTG) scheme and fixed density gradient (FDG) schemes (Lukas and Lindstrom 1991; Qu 2001; Tseng et al. 2005, 2007; Wong et al. 2007b; Hao et al. 2012): The depth distributions in $\theta$ and $\sigma_{\theta}$ were smoothed by using a five-point moving average. The temperature and density gradients were then estimated down the water column in successive 2-m depth intervals. The MLD is the depth at which the temperature gradient first reached $0.05^{\circ} \mathrm{C} \mathrm{m}^{-1}$ or the density gradient first reached $0.01,0.05$ or $0.1 \sigma_{\theta}$ unit $/ \mathrm{m}$ and they were designated as $\mathrm{MLD}_{\theta \mathrm{G}}, \mathrm{MLD}_{\sigma \mathrm{G} 1}, \mathrm{MLD}_{\mathrm{\sigma G} 5}$, and $\mathrm{MLD}_{\mathrm{\sigma G} 10}$, respectively.

(4) Maximum density gradient (MDG) scheme (Zawada et al. 2005): After the $\sigma_{\theta}$ profile was smoothed using a fivepoint moving average, the density gradient was computed down the water column at successive 2-m depth intervals. The MLD is the depth at which the maximum value was found and it was designated as $M L D_{\mathrm{mdg}}$.

\subsection{Comparison Among Methods}

Since $\mathrm{MLD}_{\mathrm{T} 8}$ have been used widely for estimating MLD in the global oceans (Kara et al. 2000) and in the South China Sea (Qu et al. 2007), it is used here as the reference value for evaluating the performance of other methods. The performance of other MLDs is evaluated using the root mean square error (RMSE) and the mean absolute percentage difference (MAPD) relative to the exact correspondence such that:

$$
\begin{aligned}
& \operatorname{RMSE}=\left[\sum\left(\mathrm{MLD}_{2}-\mathrm{MLD}_{1}\right)^{2} / \mathrm{n}\right]^{1 / 2} \\
& \operatorname{MAPD}(\%)=100\left\{\sum\left[\left|\left(\mathrm{MLD}_{2}-\mathrm{MLD}_{1}\right)\right| / \mathrm{MLD}_{1}\right]\right\} / \mathrm{n}
\end{aligned}
$$

Here, $\mathrm{n}$ is the number of occurrences; $\mathrm{MLD}_{2}$ and $\mathrm{MLD}_{1}$ 
are the MLD from any of the other nine methods and the corresponding $\mathrm{MLD}_{\mathrm{T} 8}$ respectively. Furthermore, in order to take constant methodological biases into account, the performance of the other methods is also evaluated using the RMSE and the MAPD relative to the best-fit line in a Model II regression analysis between the MLDs from one of the other nine methods and the corresponding $\mathrm{MLD}_{\mathrm{T} 8}$.

When multiple CTD profiles were available during the station occupation in a given cruise, the profile with the $\mathrm{MLD}_{\mathrm{T} 8}$ closest to the average $\mathrm{MLD}_{\mathrm{T} 8}$ in all of the profiles was used for the comparison among the methods and for evaluating the MLD seasonal climatology. The other profiles collected at the station during the cruise were used for evaluating the diurnal variability.

\subsection{Remotely Sensed Data}

The Optimum Interpolation (OI) daily average sea surface temperatures (SST; version 2), between 17.5 and $18.5^{\circ} \mathrm{N}$ and 115.3 and $116.3^{\circ} \mathrm{E}$ from 1997 to 2013 , collected by the Advanced Very High Resolution Radiometer (AVHRR) and the corresponding daily average wind speeds generated by blending observations from multiple satellites (Zhang et al. 2006), both with a spatial resolution of $0.25 \times$ $0.25^{\circ}$, were downloaded from the National Climatic Data Center (NCDC) webpages (http://www.ncdc.noaa.gov/sst/ and http://www.ncdc.noaa.gov/oa/rsad/air-sea/seawinds. $\underline{\mathrm{html}}$ ) of the NOAA. The values on the sampling dates during the cruises were used for calculating the monthly averages during those dates.

\section{RESULTS}

\subsection{Statistics of Data Availability}

Stations were occupied in 64 cruises between 17.5 and $18.5^{\circ} \mathrm{N}$ and 115.3 and $116.3^{\circ} \mathrm{E}$ over 16 years between 1997 and 2013 (Table 1). Forty three or $67 \%$ of these occupations were part of the SEATS where repeated salinity and temperature profiles were generally available. As a result, data from a total of 702 CTD casts were available for examination. Stations were occupied during all of the years and in all the months of the year. Among the years, the number of occupations per year ranged between one in 2009 to 2012 to seven in 2000. Among the months, with the exception of the month of February when the station was occupied only once, there were at least three occupations in each of the other eleven months. The maximum number of occupations, ten, was found in October. A total of 28, 22, 4, and $10 \mathrm{oc}-$ cupations occurred during the northeast monsoonal season, the southwest monsoonal season, and, in May and in October in the inter-monsoonal periods, respectively (Tseng et al. 2005; Wong et al. 2007b; Pan et al. 2015). Thus, all the seasons were reasonably well sampled through the years so that the statistics estimated from this data set may be evalu- ated with some confidence

\subsection{Principal Types of Density and Thermal Structures in the Upper Waters at SEATS}

A noticeable structural characteristic in the vertical distributions of $\theta$ and $\sigma_{\theta}$ in the upper waters at the SEATS site from the sea surface to the Tropical Water core in the permanent thermocline and pycnocline was its diversity, ranging not just from a thicker to a thinner mixed layer as expected in response to seasonal cooling, warming and changes in wind speed but also from the presence to absence of a clearly definable mixed layer. These hydrographic structures may be sub-divided into three principal types: the classical type, the stepwise type, and the graded type. Representative examples of the profiles of $\theta$, salinity and $\sigma_{\theta}$ in these three types of upper waters are shown in Figs. $2 \mathrm{a}-\mathrm{c}$. In all cases the $\theta$ and $\sigma_{\theta}$ distributions usually resemble mirror images of each other. On the other hand, while the salinity distribution is in general similar to that of $\sigma_{\theta}$ (Fig. 2a), on occasion, they can diverge from each other in some depth intervals (Figs. 2b and c), suggesting that the changes in $\sigma_{\theta}$ is controlled primarily by changes in temperature rather than salinity.

In a classical type hydrographic structure (Fig. 2a); a surface mixed layer with almost no to a gentle depth-gradient in $\theta$ and $\sigma_{\theta}$ overlies the main thermocline and pycnocline. The boundary between the mixed layer and the underlying thermocline or pycnocline is clearly marked by an abrupt change in the depth-gradients. While the variations in $\theta$ and $\sigma_{\theta}$ in the surface mixed layer usually do not exceed $0.8^{\circ} \mathrm{C}$ and $0.125 \sigma_{\theta}$ unit respectively, the widely-used threshold-values for defining the mixed layer (e.g., Miller 1976; Levitus 1982; Huang and Russell 1994; Kara et al. 2000), they can be exceeded occasionally. In the stepwise type (Fig. 2b), one or more small stepwise decreases in $\theta$ and/or increases in $\sigma_{\theta}$ can be found in the surface mixed layer above the main thermocline and pycnocline. Thus, the surface mixed layer is made up of approximately isothermal and/or isopycnic sub-layers or sub-layers with gentle depthgradients in $\theta$ and $\sigma_{\theta}$. The sum of these stepwise decreases in $\theta$ or increases in $\sigma_{\theta}$ can exceed $0.8^{\circ} \mathrm{C}$ and $0.125 \sigma_{\theta}$ unit. The graded type (Fig. 2c) is characterized by a gradual decrease in $\theta$ and increase in $\sigma_{\theta}$ with depth into the main thermocline and pycnocline. An abrupt change in the depth-gradients to mark the boundary between the mixed layer and the main thermocline or pycnocline is not clearly evident so that the MLD cannot be readily defined. In some cases, the decrease in $\theta$ and increase in $\sigma_{\theta}$ with depth are punctuated with one or more cusp-shaped segments indicating slightly steeper changes with depth (Fig. 2d). The occurrence of the graded type hydrographic structures in the upper water of the northern SCS has not been widely reported or recognized.

The type of upper water found during each cruise is listed in Table 2. The classical, stepwise and graded types 


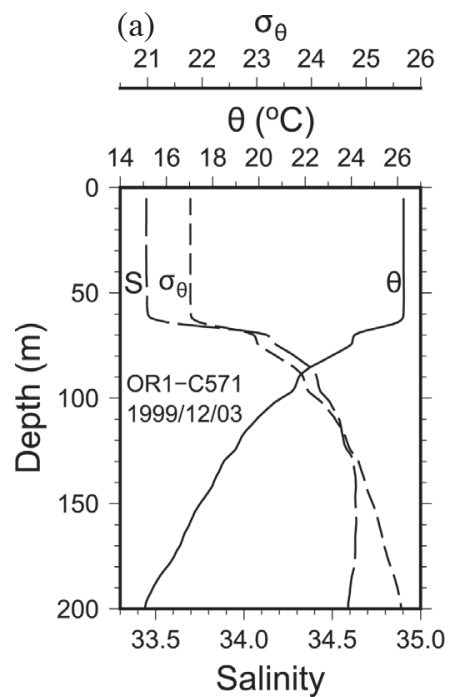

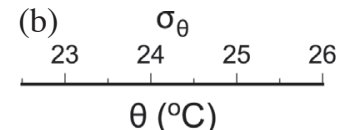

(c) $\quad \sigma_{\theta}$
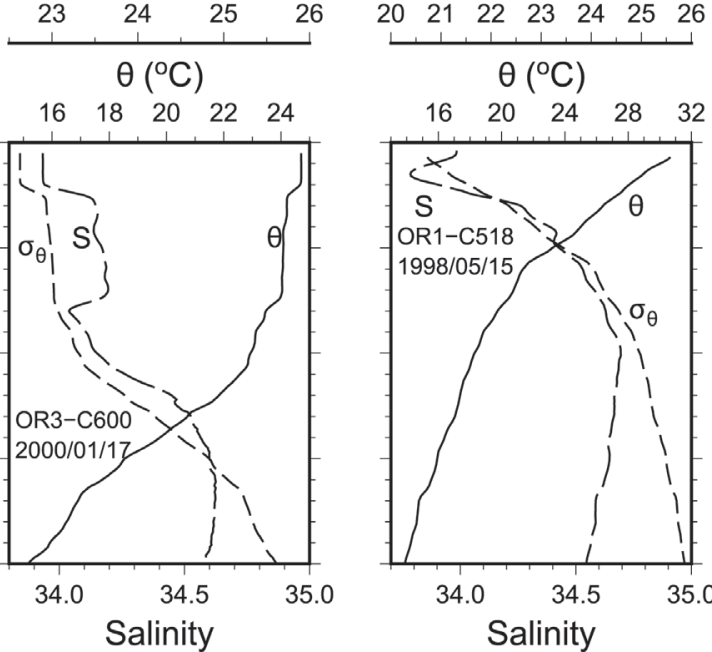

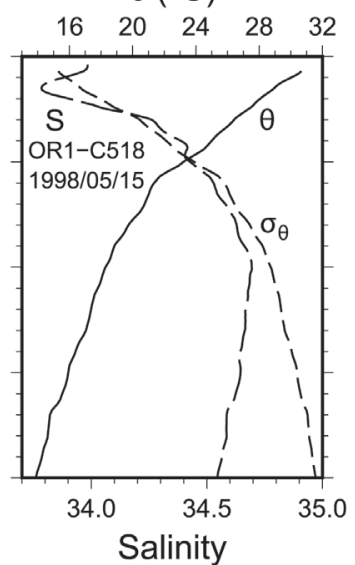

(d) $\quad \sigma_{\theta}$
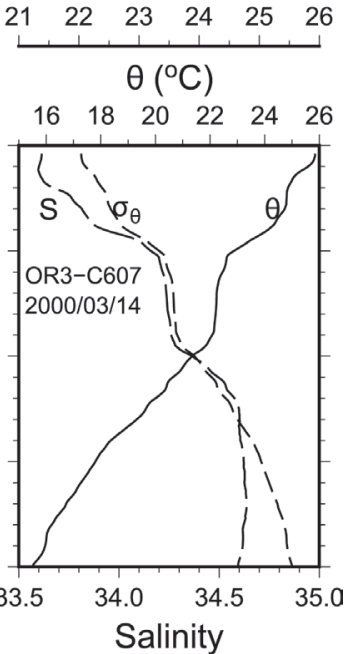

Fig. 2. The distributions of $\theta$, salinity and $\sigma_{\theta}$ in the principal types of hydrographic structures found in the upper water at the SEATS station and its vicinity, (a) classical type on 3 December 1999; (b) stepwise type on 17 January 2000; (c) graded type on 15 May 1998; (d) a variant of the graded type on 14 March 2000.

Table 2. Statistics for the types of hydrographic structures in the mixed layer.

\begin{tabular}{|c|c|c|c|c|c|c|c|c|c|c|c|c|c|c|c|}
\hline \multirow{2}{*}{ Year } & \multirow{2}{*}{ January } & \multirow{2}{*}{ February } & \multirow{2}{*}{ March } & \multirow{2}{*}{ April } & \multirow{2}{*}{ May } & \multirow{2}{*}{ June } & \multirow{2}{*}{ July } & \multirow{2}{*}{ August } & \multirow{2}{*}{ September } & \multirow{2}{*}{ October } & \multirow{2}{*}{ November } & \multirow{2}{*}{ December } & \multicolumn{3}{|c|}{ Annual Type Total } \\
\hline & & & & & & & & & & & & & (a) & (b) & (c) \\
\hline 1997 & - & - & - & $\mathrm{c}$ & - & $\mathrm{a}$ & - & - & - & a & - & - & 2 & 0 & 1 \\
\hline 1998 & - & - & - & - & $\mathrm{c}$ & a & - & - & - & - & - & - & 1 & 0 & 1 \\
\hline 1999 & - & - & - & a & - & - & - & $\mathrm{b}$ & $\mathrm{a}, \mathrm{a}$ & - & a & a & 5 & 1 & 0 \\
\hline 2000 & $\mathrm{~b}$ & - & $\mathrm{b}, \mathrm{c}$ & - & $\mathrm{a}$ & - & $\mathrm{a}, \mathrm{b}$ & - & - & a & - & - & 3 & 3 & 1 \\
\hline 2001 & - & a & $\mathrm{c}$ & - & - & $\mathrm{a}$ & - & - & - & $\mathrm{a}, \mathrm{a}$ & - & $\mathrm{a}$ & 5 & 0 & 1 \\
\hline 2002 & - & - & $\mathrm{a}, \mathrm{a}$ & - & - & - & c & - & a & $\mathrm{a}$ & a & - & 5 & 0 & 1 \\
\hline 2003 & $\mathrm{~b}$ & - & $\mathrm{c}$ & - & - & - & $\mathrm{a}$ & $\mathrm{c}$ & - & a & - & $\mathrm{a}$ & 3 & 1 & 2 \\
\hline 2004 & - & - & $\mathrm{c}$ & - & $\mathrm{a}$ & $\mathrm{a}$ & - & a & - & - & $\mathrm{a}$ & - & 4 & 0 & 1 \\
\hline 2005 & $\mathrm{a}$ & - & $\mathrm{a}$ & - & - & - & $\mathrm{a}$ & - & - & - & $\mathrm{b}$ & $\mathrm{a}$ & 4 & 1 & 0 \\
\hline 2006 & - & - & - & - & - & $\mathrm{a}$ & $\mathrm{a}, \mathrm{a}$ & $\mathrm{a}$ & - & $\mathrm{a}$ & - & - & 5 & 0 & 0 \\
\hline 2007 & $\mathrm{a}, \mathrm{c}$ & - & - & - & - & - & $\mathrm{a}$ & - & - & $\mathrm{a}$ & - & - & 3 & 0 & 1 \\
\hline 2008 & - & - & - & - & $\mathrm{a}$ & - & - & - & - & - & - & $\mathrm{a}$ & 2 & 0 & 0 \\
\hline 2009 & - & - & - & - & - & - & $\mathrm{a}$ & - & - & - & - & - & 1 & 0 & 0 \\
\hline 2010 & - & - & - & - & - & - & - & - & - & a & - & - & 1 & 0 & 0 \\
\hline 2011 & - & - & - & - & - & - & - & - & - & - & - & $\mathrm{a}$ & 1 & 0 & 0 \\
\hline 2012 & - & - & - & - & - & - & - & $\mathrm{a}$ & - & - & - & - & 1 & 0 & 0 \\
\hline 2013 & - & - & - & $\mathrm{c}$ & - & - & - & - & - & $\mathrm{a}$ & - & $\mathrm{a}$ & 2 & 0 & 1 \\
\hline \multicolumn{13}{|c|}{ Monthly Type Total } & \multicolumn{3}{|c|}{ Type Total } \\
\hline (a) & 2 & 1 & 3 & 1 & 3 & 5 & 7 & 3 & 3 & 10 & 3 & 7 & $\begin{array}{c}48 \\
(75 \%)\end{array}$ & & \\
\hline (b) & 2 & 0 & 1 & 0 & 0 & 0 & 1 & 1 & 0 & 0 & 1 & 0 & & $\begin{array}{c}6 \\
(10 \%)\end{array}$ & \\
\hline \multirow[t]{2}{*}{ (c) } & 1 & 0 & 4 & 2 & 1 & 0 & 1 & 1 & 0 & 0 & 0 & 0 & & & $\begin{array}{c}10 \\
(15 \%)\end{array}$ \\
\hline & & Northeast $\mathrm{m}$ & onsoon & & I & & South & west mor & nsoon & I & Northeast & Monsoon & & & \\
\hline
\end{tabular}


were found in 48,6 and 10 or 75,10 , and $15 \%$ of the cruises respectively. Thus, although the classical type was by far the most prevalent and could be found throughout the year, the occurrences of the remaining two atypical minor types were clearly not negligible. There was no clear seasonality in the stepwise type. In 5 out of the 6 cases, the stepwise density and temperature structures coincided well with each other. In the remaining case, the stepwise density structure was accompanied by a basic isothermal mixed layer, indicating that temperature changes did not contribute to the density structure formation. Instead, the stepwise density structure could be traced to the presence of a sub-layer of slightly more saline water overlying the main thermocline and pycnocline as found on 21 January 2003 (Fig. 3). This phenomenon was similar to the barrier layer, which has been found in other parts of the oceans (Kara et al. 2000). Based on the present data-set, it would be difficult to pinpoint the cause of these atypical hydrographic structures as the data were collected essentially at a single location so that the advective process effects, if any, cannot be taken into consideration. Aside from advection, conceivably, a stepwise hydrographic structure may be formed by the interleaving of a cooling episode with stronger vertical mixing with a warming episode with weaker vertical mixing.

In contrast, the graded upper water was found almost exclusively between March and August during the surface water progressive warming period under generally weaker wind throughout the year (Tseng et al. 2007; Pan et al. 2015). Vertical mixing is minimized under this combination of environmental conditions. Small scale processes such as eddy diffusion may become the major mechanism for the transfer of heat from the sea surface to the sub-surface and this may result in the graded type of upper water. Conceivably, if the warming period is punctuated by more effective vertical mixing events, such as strong wind events, the cusped shape segments in the density and temperature profiles may then be found. Whether the stepwise and graded types of upper water are transitory or sufficiently permanent to be representative of the climatological monthly or seasonal characteristics of the upper water is uncertain. The predominance of the classical type throughout the year tends to suggest that the two minor types may be transitory as there may be sufficient periods of effective vertical advective mixing by wind and/or cooling during the seasons to transform the minor types into the classical type of upper water. Nonetheless, given the low sampling frequency in the present dataset, neither possibility can yet be definitively ruled out.

\subsection{Estimating MLD at the SEATS Station and Its Vicinity - Methodological Dependence}

\subsubsection{Classical Type Upper Water Hydrographic Structure}

Out of the ten methods for estimating MLD, MLD could not be estimated as MLD $\mathrm{OG}_{5}$ and $\mathrm{MLD}_{\sigma \mathrm{G} 10}$ in the classical type upper water in 1 and 4 out of the 49 cruises as the density gradient never reached the prescribed value. Thus, for their lack of universal applicability, these methods are not recommended for MLD estimation in these tropical waters. However, in those cases where $\mathrm{MLD}_{\mathrm{\sigma G} 5}$ and $\mathrm{MLD}_{\sigma \mathrm{G} 10}$ could be determined, they did correlate reasonable well with $\mathrm{MLD}_{\mathrm{T}}$, especially when a constant offset was allowed (Fig. 4; Table 3). The relationships between MLD $_{\mathrm{T} 8}$ and the MLD obtained from the remaining seven methods are also shown in Fig. 4. Among these seven methods, MLD $_{\mathrm{T} 5}$, $\mathrm{MLD}_{\mathrm{T} 10}$, and $\mathrm{MLD}_{\theta \mathrm{G}}$ were more consistent with $\mathrm{MLD}_{\mathrm{T} 8}$. Most of the data points fell within $\pm 5 \mathrm{~m}$ and no data point fell outside of $\pm 20 \mathrm{~m}$ of the 1:1 line. The RMSE-s were \pm 3 , \pm 2 , and \pm 6 m respectively while the corresponding MAPD-s were 5,3 , and $12 \%$ (Table 3 ). These values were relatively small and indicate that these four methods yielded similar MLDs. The correspondence improved when a constant offset was allowed in a Model II regression analysis as the RMSE-s relative to the best-fit lines were reduced to $\pm 2, \pm 2$, and $\pm 4 \mathrm{~m}$ respectively while the MAPD-s were reduced to 4 , 2 , and $5 \%$. The best-fit lines yielded slopes of $1.01 \pm 0.02$, $1.00 \pm 0.01$, and $0.98 \pm 0.03$, intercepts of $-2 \pm 1,1 \pm 1$, and $-3 \pm 1 \mathrm{~m}$, and correlation coefficients of $0.99,1.00$, and 0.98 for $\mathrm{MLD}_{\mathrm{T} 5}, \mathrm{MLD}_{\mathrm{T} 10}$, and $\mathrm{MLD}_{\theta \mathrm{G}}$ respectively (Table 3). All of the slopes included unity within the statistical uncertainties while the intercepts were equal to or only slightly larger than the statistical uncertainties, indicating that once a small

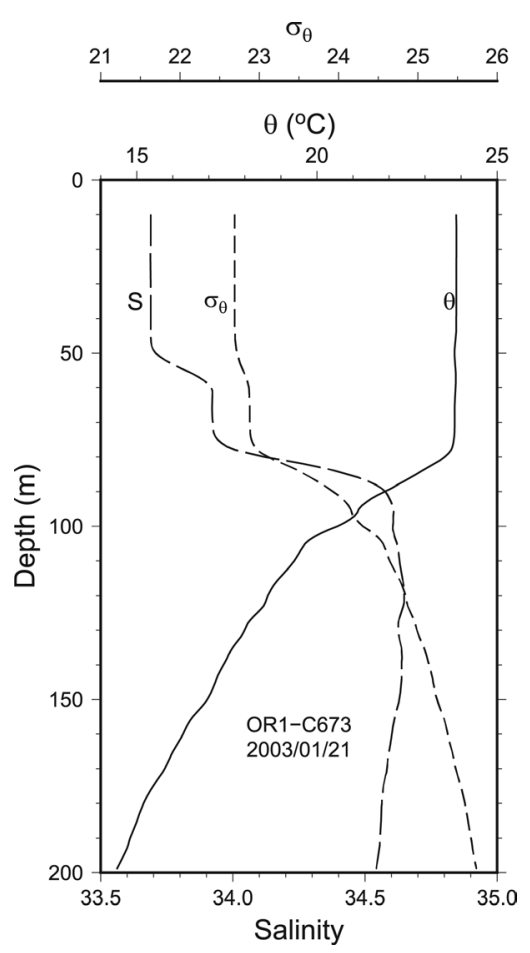

Fig. 3. The distribution of potential temperature $\theta$, salinity and $\sigma_{\theta}$ on 21 January 2003 when a stepwise type mixed layer was found. 

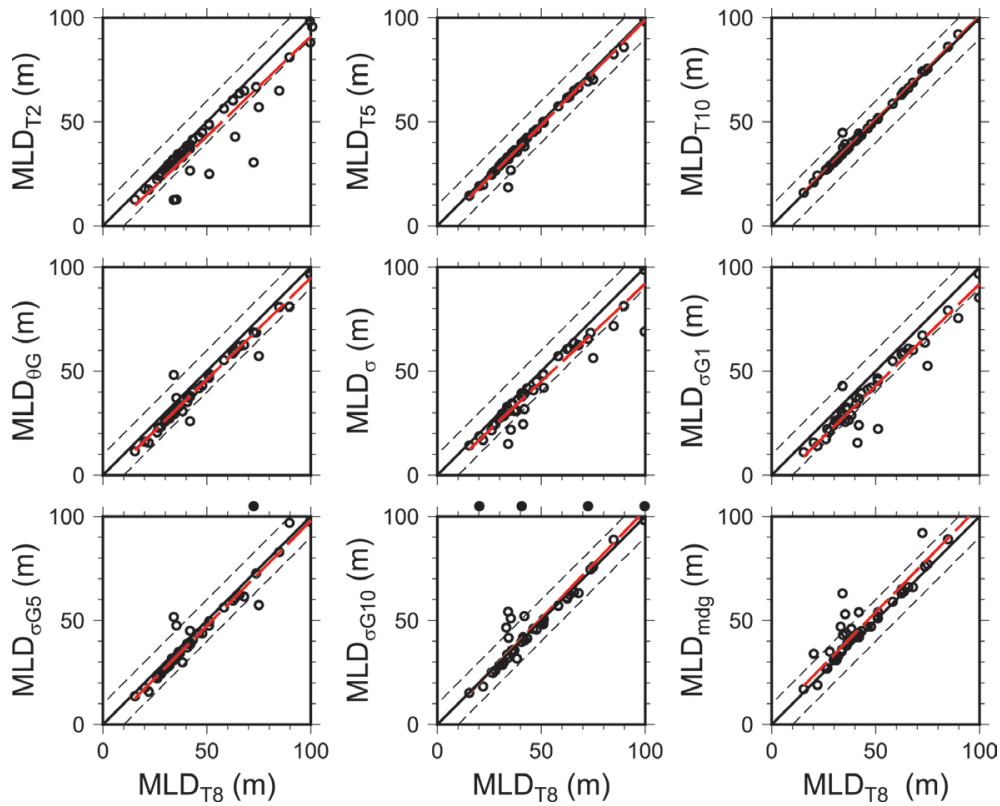

Fig. 4. Relationships between the other nine MLDs and $\mathrm{MLD}_{\mathrm{T}}$ in the classical type mixed layer. Solid line: 1:1 line; short dashed line: $\pm 10 \mathrm{~m}$ from 1:1 line; red long dashed line: best fit by Model II regression analysis. Dots above the upper axis of the figure indicate $\mathrm{MLD}_{\mathrm{T} 8}$ at which MLD $_{\mathrm{OG} 5}$ and/ or $\mathrm{MLD}_{\mathrm{oG} 10}$ could not be estimated. (Color online only)

Table 3. Model II linear regression analyses results relative to $\mathrm{MLD}_{\mathrm{T} 8}$.

\begin{tabular}{|c|c|c|c|c|c|c|c|c|c|c|}
\hline Type & Statisitcal Parameter & MLD $_{\mathrm{T} 2}$ & $\mathbf{M L D}_{\mathrm{T5}}$ & MLD $_{\mathrm{T} 10}$ & $\mathbf{M L D}_{\theta \mathrm{G}}$ & MLD $_{\sigma}$ & MLD $_{\sigma \mathrm{G} 1}$ & MLD $^{*}{ }_{\mathrm{GG} 5}$ & MLD $_{\sigma \mathrm{G} 10}^{*}$ & MLD $_{\text {mdg }}$ \\
\hline \multirow{10}{*}{ Classical } & $\mathrm{A}$ & -5 & -2 & 1 & -3 & -2 & -6 & -3 & -1 & 3 \\
\hline & B & 0.96 & 1.01 & 1.00 & 0.98 & 0.94 & 0.98 & 1.01 & 1.04 & 1.02 \\
\hline & $\sigma_{\mathrm{A}}$ & 3 & 1 & 1 & 1 & 2 & 2 & 2 & 2 & 2 \\
\hline & $\sigma_{\mathrm{B}}$ & 0.05 & 0.02 & 0.01 & 0.03 & 0.04 & 0.04 & 0.03 & 0.04 & 0.04 \\
\hline & $\gamma$ & 0.92 & 0.99 & 1.00 & 0.98 & 0.96 & 0.96 & 0.98 & 0.97 & 0.96 \\
\hline & $\operatorname{RMSE}_{1}(\mathrm{~m})$ & 11 & 3 & 2 & 6 & 8 & 9 & 5 & 5 & 7 \\
\hline & $\mathrm{MPD}_{1}(\%)$ & 14 & 5 & 3 & 12 & 11 & 18 & 10 & 8 & 11 \\
\hline & $\operatorname{RMSE}_{2}(\mathrm{~m})$ & 8 & 2 & 2 & 4 & 6 & 6 & 5 & 5 & 6 \\
\hline & $\mathrm{MPD}_{2}(\%)$ & 19 & 4 & 2 & 5 & 11 & 13 & 5 & 8 & 9 \\
\hline & $\mathrm{N}$ & 48 & 48 & 48 & 48 & 48 & 48 & 47 & 44 & 48 \\
\hline \multirow{10}{*}{ Stepwise } & A & -33 & -22 & 2 & -35 & -21 & -13 & -9 & 7 & -5 \\
\hline & B & 1.17 & 1.07 & 1.00 & 1.17 & 0.94 & 0.66 & 0.99 & 0.89 & 0.99 \\
\hline & $\sigma_{\mathrm{A}}$ & 19 & 19 & 1 & 19 & 16 & 10 & 22 & 1 & 23 \\
\hline & $\sigma_{\mathrm{B}}$ & 0.32 & 0.31 & 0.01 & 0.32 & 0.26 & 0.17 & 0.36 & 0.02 & 0.37 \\
\hline & $\gamma$ & 0.73 & 0.70 & 1.00 & 0.73 & 0.73 & 0.78 & 0.48 & 1.0 & 0.39 \\
\hline & $\operatorname{RMSE}_{1}(\mathrm{~m})$ & 28 & 23 & 2 & 30 & 28 & 34 & 22 & 3 & 22 \\
\hline & $\mathrm{MPD}_{1}(\%)$ & 46 & 32 & 3 & 49 & 45 & 58 & 14 & 5 & 21 \\
\hline & $\operatorname{RMSE}_{2}(\mathrm{~m})$ & 16 & 16 & 1 & 16 & 13 & 8 & 19 & 1 & 21 \\
\hline & $\mathrm{MPD}_{2}(\%)$ & 55 & 40 & 1 & 61 & 41 & 30 & 49 & 2 & 50 \\
\hline & $\mathrm{N}$ & 6 & 6 & 6 & 6 & 6 & 6 & 6 & 4 & 6 \\
\hline \multirow{10}{*}{$\begin{array}{c}\text { Classical + } \\
\text { Stepwise }\end{array}$} & $\mathrm{A}$ & -8 & -4 & 1 & -7 & -5 & -9 & -3 & -1 & 2 \\
\hline & $\mathrm{B}$ & 0.98 & 1.01 & 1.00 & 1.02 & 0.95 & 0.98 & 1.01 & 1.03 & 1.01 \\
\hline & $\sigma_{\mathrm{A}}$ & 4 & 3 & 1 & 3 & 3 & 3 & 3 & 2 & 3 \\
\hline & $\sigma_{\mathrm{B}}$ & 0.07 & 0.05 & 0.01 & 0.06 & 0.06 & 0.06 & 0.05 & 0.03 & 0.06 \\
\hline & $\gamma$ & 0.87 & 0.94 & 0.92 & 0.91 & 0.90 & 0.88 & 0.93 & 0.97 & 0.90 \\
\hline & $\operatorname{RMSE}_{1}(\mathrm{~m})$ & 14 & 8 & 2 & 11 & 12 & 14 & 9 & 5 & 10 \\
\hline & $\operatorname{MPD}_{1}(\%)$ & 18 & 8 & 3 & 16 & 15 & 22 & 10 & 8 & 12 \\
\hline & $\mathrm{RMSE}_{2}(\mathrm{~m})$ & 11 & 7 & 2 & 9 & 9 & 10 & 8 & 5 & 10 \\
\hline & $\mathrm{MPD}_{2}(\%)$ & 29 & 12 & 2 & 18 & 20 & 27 & 9 & 7 & 12 \\
\hline & $\mathrm{N}$ & 54 & 54 & 54 & 54 & 54 & 54 & 53 & 48 & 54 \\
\hline
\end{tabular}


offset was taken into account, all four methods gave virtually identical results so that valid inter-comparisons may be made among them.

In the remaining four methods, while a majority of the data points fell within $\pm 5 \mathrm{~m}$ from the 1:1 line relative to $\mathrm{MLD}_{\mathrm{T} 8}$, there were notable exceptions that fell more than $\pm 20 \mathrm{~m}$ away (Fig. 4). The larger deviations were exclusively under-estimations in $\mathrm{MLD}_{\mathrm{T} 2}, \mathrm{MLD}_{\sigma}$ and $\mathrm{MLD}_{\sigma \mathrm{G} 1}$, and overestimations in MLD $_{\mathrm{mdg}}$. The RMSE and MAPD relative to the $1: 1$ line ranged between \pm 7 and $\pm 11 \mathrm{~m}$ and 11 and $18 \%$ respectively (Table 3 ). In the Model II linear regression analyses of these relationships, the slope between MLD $_{0}$ and $\mathrm{MLD}_{\mathrm{T} 8}, 0.94 \pm 0.04$, did not include unity within its statistical uncertainty, indicating that they cannot be used interchangeably even allowing for a correction for an offset. In the remaining three cases, the slopes for $\mathrm{MLD}_{\mathrm{T} 2}$, $\mathrm{MLD}_{\sigma \mathrm{G} 1}$, and $\mathrm{MLD}_{\mathrm{mdg}}, 0.96 \pm 0.05,0.98 \pm 0.04$, and $1.02 \pm$ 0.04 , did include unity within their statistical uncertainties, although the correlation coefficient with $\mathrm{MLD}_{\mathrm{T} 2}$ was a bit lower than those of the other two. The relationship intercepts were $-5 \pm 3,-6 \pm 2$, and $3 \pm 2 \mathrm{~m}$, indicating that there were statistically significant offsets in all three cases. The corresponding RMSE-s and MAPD-s, $\pm 8, \pm 6$, and $\pm 6 \mathrm{~m}$, and 19,11 , and $9 \%$ respectively, were larger than those of $\mathrm{MLD}_{\mathrm{T} 5}, \mathrm{MLD}_{\mathrm{T} 10}$, and $\mathrm{MLD}_{\theta \mathrm{G}}$. Thus, while $\mathrm{MLD}_{\mathrm{T} 2}, \mathrm{MLD}_{\sigma \mathrm{G} 1}$, and $\mathrm{MLD}_{\text {mdg }}$ can also yield MLDs that are essentially identical to $\mathrm{MLD}_{\mathrm{T} 8}$ after a constant offset has been taken into account, the uncertainty is larger. Among them, the RMSE and MAPD of MLD mdg were the lowest and came close to those of $\mathrm{MLD}_{\mathrm{T} 5}, \mathrm{MLD}_{\mathrm{T} 10}$, and $\mathrm{MLD}_{\theta \mathrm{G}}$. In previous studies, $\mathrm{MLG}_{\mathrm{T} 8}\left(\mathrm{Qu}\right.$ et al. 2007), MLD ${ }_{\theta \mathrm{G}}(\mathrm{Qu}$ 2001; Ge et al. 2003; Hao et al. 2012), MLD ${ }_{\sigma G 5}$ (Tseng et al. 2007), and MLD (Tseng et al. 2005, 2009; Wong et al. 2007a, b) have been used for estimating MLD in the SCS. Only the results in the first two sets of studies may be readily compared to each other even after a constant offset has been applied.

An examination of the $\theta$ and $\sigma_{\theta}$ depth profiles associated with the cases where $\mathrm{MLD}_{\mathrm{T} 2}, \mathrm{MLD}_{\sigma}, \mathrm{MLD}_{\sigma \mathrm{G} 1}$, and $M L D_{\text {mdg }}$ differed significantly from $M D_{\mathrm{T}}$ indicates that these profiles fell into two sub-types (Fig. 5). In the first sub-type, while there was a marked change in the $\theta$ and $\sigma_{\theta}$ gradients with depth between the surface mixed layer and the main thermocline and pycnocline, there were gentle but noticeable depth-gradients in $\theta$ and $\sigma_{\theta}$ within the surface mixed layer. In some cases, the gradients were uniform with depth. In other cases, the gradients varied with depth. In all cases, as a result of these gradients, the FTD, FDD, and FDG schemes could fail to capture the base of the mixed layer as indicated by visual inspection. Instead, they could designate as MLD a depth that was within the mixed layer and was shallower than the $\mathrm{MLD}_{\mathrm{T} 8}$ (Fig. 5a), and the discrepancy was larger when a smaller fixed temperature difference, a smaller fixed density difference or a smaller fixed density gradient was used to define the MLD. Thus, while $\mathrm{MLD}_{\sigma}$, MLD $_{\text {oG } 1}$ have been widely used for estimating the MLD in other parts of the oceans, they may not be the most appropriate in the tropical waters such as those in the northern South China Sea. In the second sub-type, since $\theta$ decreased while
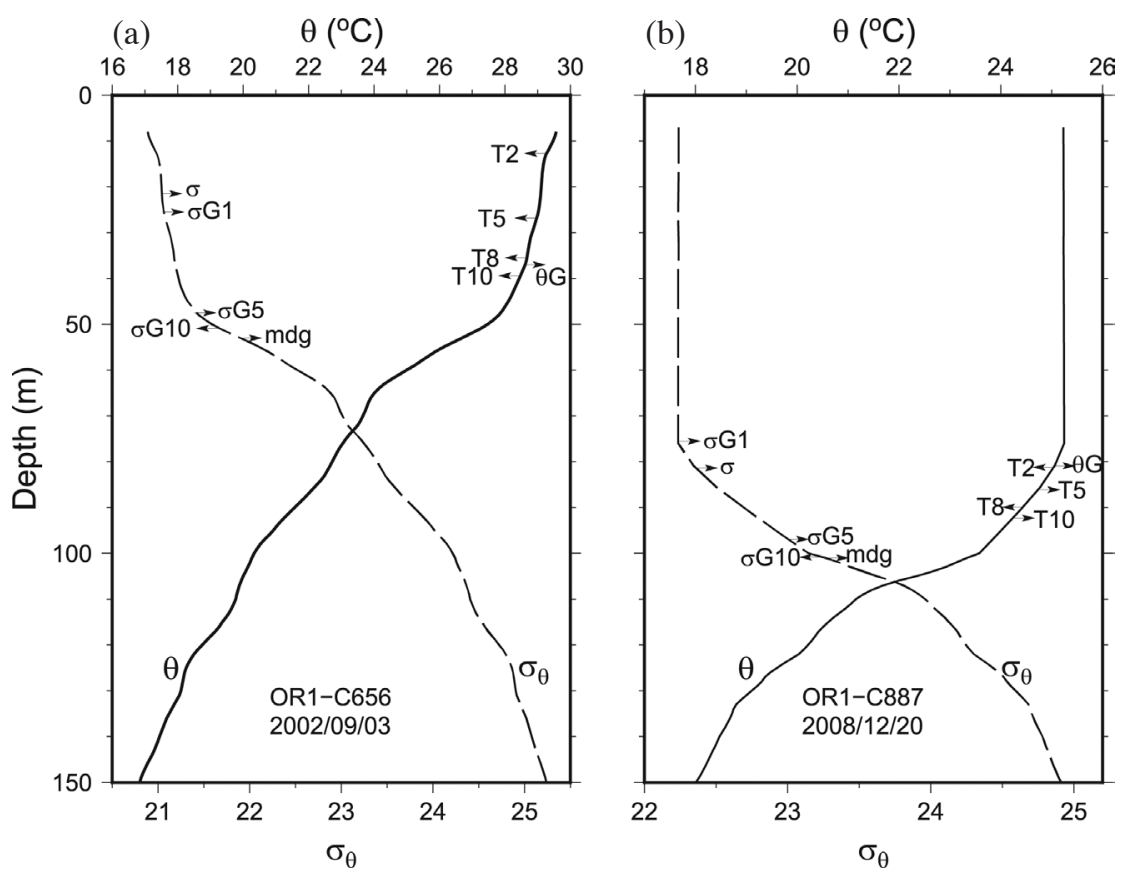

Fig. 5. Sub-classes in the classical type mixed layer: (a) with significant gradients in $\theta$ and $\sigma_{\theta}$ in the mixed layer on 3 September 2002 ; (b) with gentle gradient in $\theta$ and $\sigma_{\theta}$ in the upper thermocline and pycnocline on 20 December 2008. The arrows indicate the MLDs estimated by the ten methods as labeled by the subscripts of the MLDs. 
$\sigma_{\theta}$ increased gradually rather than abruptly with depth in the upper-most part of the thermocline and pycnocline immediately below the mixed layer, they gave rise to cusp-shaped profiles in the depth interval. As a result, the different FTD and FDD schemes would designate different depths within that depth interval as the MLD (Fig. 5b). Again, those MLDs defined by a smaller fixed temperature decrease, a smaller fixed density increase, a smaller temperature gradient or a smaller density gradient would yield shallower MLDs.

\subsubsection{Stepwise Type Upper Water Hydrographic Structure}

In the stepwise type of upper water hydrographic structure, $\mathrm{MLD}_{\mathrm{GG} 10}$ could not be determined in two out of the six cases. In the remaining eight schemes, relative to the 1:1 line, only $\mathrm{MLD}_{\mathrm{T} 10}$ correlated well with $\mathrm{MLD}_{\mathrm{T} 8}$, yielding RMSE and MAPD of $\pm 2 \mathrm{~m}$ and 3\% (Fig. 6; Table 3). The rest deviated significantly from the 1:1 relationship with many data points falling more than -20 m away, yielding large RMSE-s and MAPD-s ranging between \pm 22 and $\pm 34 \mathrm{~m}$ and 14 and $58 \%$ respectively. The large deviations were exclusively a bias towards shallower MLDs. When a constant offset was allowed, in the Model II regression analyses, the correlation coefficient between $\mathrm{MLD}_{\mathrm{T} 10}$ and $\mathrm{MLD}_{\mathrm{T} 8}$ was 1.00 , with a slope of $1.00 \pm 0.01$ and an intercept of $2 \pm 1 \mathrm{~m}$. For the rest, the correlation coefficient and the MAPD varied between 0.39 and 0.78 , and 30 and $61 \%$ respectively. A visual inspection of the $\theta$ and $\sigma_{\theta}$ profiles where large deviations from the 1:1 relationship were found indicates that these other methods failed to capture the bottom of the surface mixed layer and would designate the depth of one of the smaller stepwise changes in $\theta$ or $\sigma_{\theta}$ within the surface mixed layer as the MLD. As a result, shallower MLDs were estimated.

\subsubsection{Determining MLD in the Classical Type and Stepwise Type Water Together}

Taking the results from the classical and the stepwise types of water together, only $\mathrm{MLD}_{\mathrm{T} 8}$ and $\mathrm{MLD}_{\mathrm{T} 10}$ are internally consistent for estimating the MLDs in both types of water. By pooling the data from these two types of water, the RMSE and MAPD relative to the 1:1 line were $\pm 2 \mathrm{~m}$ and 3\%. A Model II linear regression analysis yielded a correlation coefficient of 0.92 , a slope of $1.00 \pm 0.01$, and an intercept of $1 \pm 1 \mathrm{~m}$. The corresponding RMSE and MDP relative to the best-fit line were $\pm 2 \mathrm{~m}$ and $2 \%$.

\subsection{Diurnal Variability of the MLD}

Data from 6 to 21 CTD casts were obtained in 35 occasions at the SEATS station over an 18 to $24-\mathrm{hr}$ time period between 1999 and 2013. These observations were made at least once in each month of the year. The MLD varied di- urnally. As an example, the vertical profiles of $\theta$ observed in 15 repeated CTD casts in approximately 1-2-hr intervals over a 24-hr period on 23 - 24 November 1999 are shown in Fig. 7a. The MLD varied between 43 and $58 \mathrm{~m}$ with a diurnal average and a standard deviation of 50.3 and $\pm 4.3 \mathrm{~m}$, respectively. Similar results were also found in our cruises when repeated CTD casts were conducted over 24-hr periods. The standard deviations in the estimated average $\mathrm{MLD}_{\mathrm{T} 8}$, which is a measure of the MLD variability over a diurnal cycle, observed in the different months of the year are shown in Fig. 7b. They ranged between \pm 1 and $\pm 7 \mathrm{~m}$. The maximum range of standard deviations within a given month was about $6 \mathrm{~m}$. The average standard deviation over all the months was $\pm 4.4 \mathrm{~m}$. There was no clear trend to indicate a relationship between the variability and the time of the year. The average values were \pm 4.1 and $\pm 4.7 \mathrm{~m}$ between November and April during the northeast monsoon and between June and September during the southwest monsoon and \pm 4.6 and $\pm 4.4 \mathrm{~m}$ during the two inter-monsoonal periods in May and October, respectively. Alternatively, the average standard deviations were $\pm 4.6, \pm 3.5, \pm 4.8$, and $\pm 4.4 \mathrm{~m}$ in winter, spring, summer and fall respectively. Thus, while the diurnal variation in the MLD is a common occurrence, it occurs within a relatively well-defined range. This diurnal variation should be taken into account in the MLD estimation from a once-through CTD trace as its effect can become significant when the MLD is shallow, such as the MLDs of around $20 \mathrm{~m}$ that were found during some summers at the SEATS station (Tseng et al. 2009).

\subsection{Intra-Annual Variability of the MLD}

The $\mathrm{MLD}_{\mathrm{T} 8}$ found in the different months of the year between 1999 and 2013 and their average values in each month are shown in Fig. 8a. The average MLD in each month was at its maximum of $\sim 80 \mathrm{~m}$ in December and January. It decreased steadily to $\sim 25 \mathrm{~m}$ in May. It then increased gradually and reached $\sim 35 \mathrm{~m}$ in June before it stayed approximately constant through October. It increased sharply to reach the maximum value in December/January. This intraannual pattern and the ranges of values are similar to those reported previously based on the data covering shorter time periods (Tseng et al. 2005, 2007, 2009; Wong et al. 2007a). Although the northern SCS is located in the tropical zone, its climate is sub-tropical. Convective overturn induced by surface cooling in the winter is a major control on the intraannual variations in the hydrographic characteristics in its mixed layer (Tseng et al. 2005; Pan et al. 2015). The intraannual variability in the monsoonal wind strength is considered to be another important control on the mixed layer behaviors (Tseng et al. 2005). The deeper mixed layer during the northeast monsoonal season has been explained by the combined surface cooling and stronger wind effects during this time of the year (Tseng et al. 2005). Indeed, a Model II 
regression analysis indicates that the average $\mathrm{MLD}_{\mathrm{T} 8}$ in different months of year, MLD $_{\text {avg }}$, was negatively correlated to the corresponding remotely sensed average $\mathrm{SST}, \mathrm{SST}_{\mathrm{avg}}$, and positively correlated to the corresponding remotely sensed average wind speed, $\mathrm{WS}_{\mathrm{avg}}$, on the sampling days between 1999 and 2013 (Figs. 8b and c) such that:

$\mathrm{SST}_{\mathrm{avg}}=-0.11( \pm 0.02) \mathrm{MLD}_{\text {avg }}+32( \pm 2) \mathrm{r}=-0.81 ; \mathrm{n}=12$

$\mathrm{WS}_{\mathrm{avg}}=0.12( \pm 0.03) \mathrm{MLD}_{\mathrm{avg}}+1( \pm 2) \mathrm{r}=0.63 ; \mathrm{n}=12$

where $\mathrm{r}$ is the correlation coefficient and $\mathrm{N}$ is the number of data points. During the southwest monsoonal season between June and September, the average MLDs were less variable as they stayed within a narrow range, at $30-45$ $\mathrm{m}$, and the standard deviation of the average values did not exceed $\pm 6 \mathrm{~m}$. On the other hand, during the northeast monsoonal season between November and April, the average MLDs varied by a factor of two as they ranged between $40 \mathrm{~m}$ in March/April to $80 \mathrm{~m}$ in December/January and their standard deviations, reaching $\pm 20 \mathrm{~m}$, were also larger than those during the southwest monsoon. The summer, winter and annual average MLDs calculated from the monthly averages were $35 \pm 5,80 \pm 13$, and $49 \pm 21 \mathrm{~m}$, respectively.
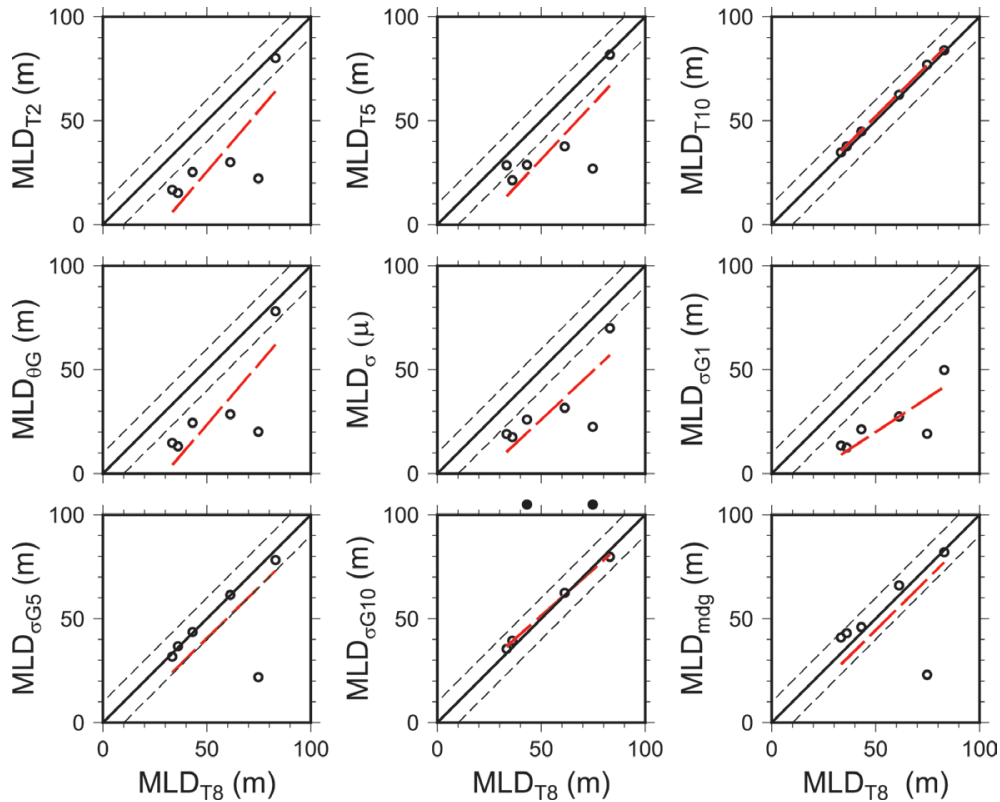

Fig. 6. Relationships between the other nine MLDs and $\mathrm{MLD}_{\mathrm{T}}$ in stepwise type mixed layer. Solid line: 1:1 line; short dashed line: $\pm 10 \mathrm{~m}$ from 1:1 line; red long dashed line: best fit by Model II regression analysis. Dots above the upper axis of the figure indicate $\mathrm{MLD}_{\mathrm{T} 8}$ at which $\mathrm{MLD}_{\sigma \mathrm{G} 10} \mathrm{Could}_{\mathrm{O}}$ not be estimated. (Color online only)
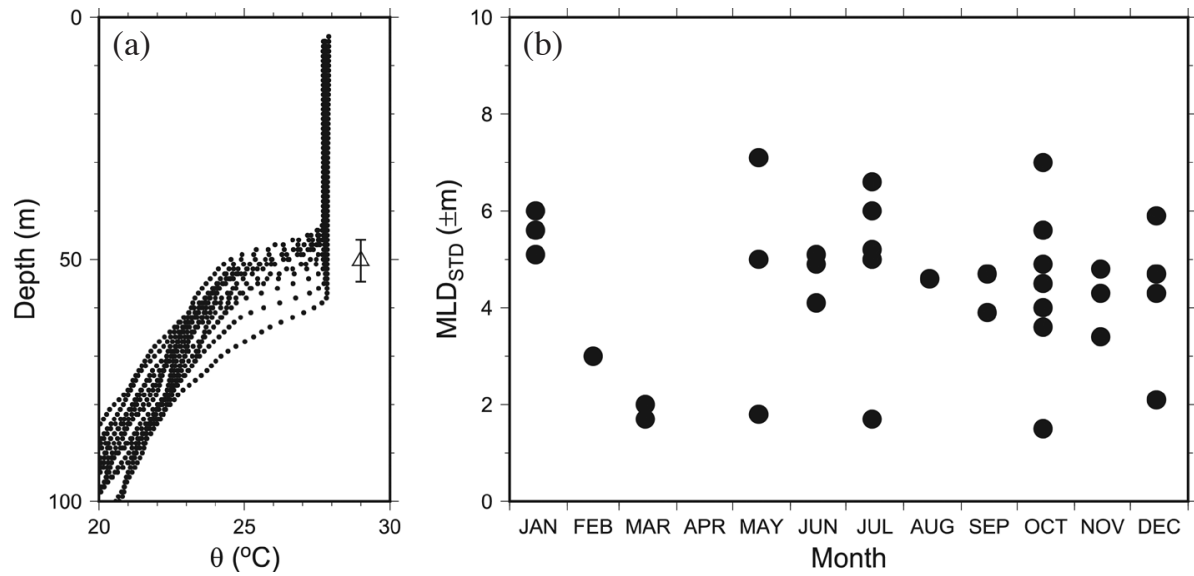

Fig. 7. (a) The 15 profiles of potential temperature $\theta$ collected over a 24 -hr period on $23-24$ November 1999 . The average $\mathrm{MLD}_{\mathrm{T}}(\Delta)$ and its standard deviation are also shown. (b) The standard deviation in MLD $_{\mathrm{T} 8}\left(\mathrm{MLD}_{\mathrm{STD}}\right)$ at the SEATS station in 35 occasions between 1999 and 2013 when the station was occupied for at least an 18-hr time period and when at least six serial CTD casts were made during the occupation of the station. 
(a)

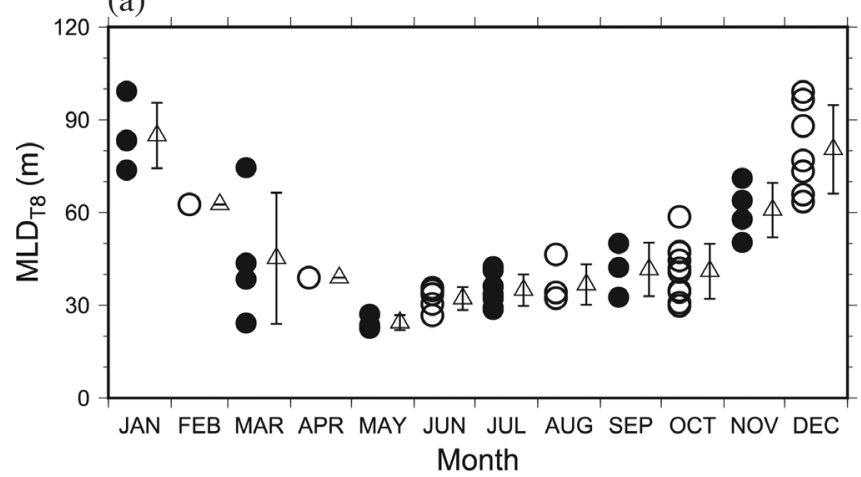

(b)

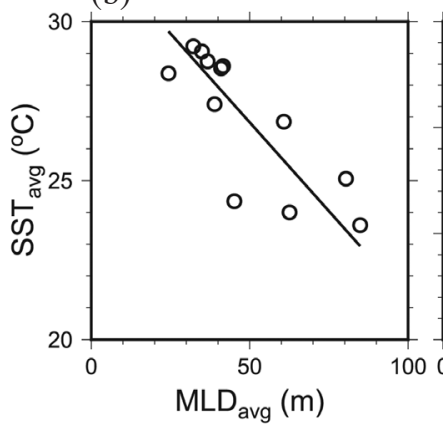

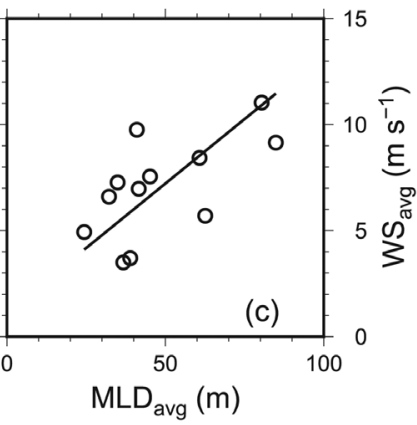

Fig. 8. (a) $\mathrm{MLD}_{\mathrm{T} 8}$ obtained in 54 occasions at the SEATS station and its vicinity between 1999 and 2013 in the different months of the year. The monthly averages $(\Delta)$ and their standard deviations are also shown. When data from multiple CTD casts were available, the average values were

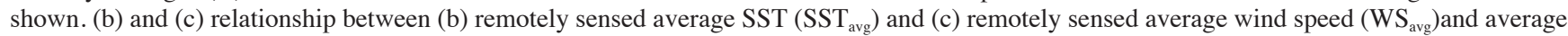
$\mathrm{MLD}_{\mathrm{T} 8}\left(\mathrm{MLD}_{\text {avg }}\right)$ on the days of sampling in the different months of the year. The Model II regression lines are also shown.

\section{SUMMARY}

The upper water hydrographic structure in the tropical northern SCS is noticeably diverse and may be classified into the classical, stepwise and graded types. This presents a challenge in estimating the MLD in these waters. In 64 station occupations at and around the SEATS station between 1997 and 2013, the MLD was indeterminate in $15 \%$ of the time when the graded type was found. In the remaining $85 \%$ of the time, among the ten more widely used methods for estimating MLD, only two, $\mathrm{MLD}_{\mathrm{T} 8}$ and $\mathrm{MLD}_{\mathrm{T} 10}$, yielded consistent results which were in qualitative agreement with visual inspection. These MLDs can basically be used interchangeable with each other. In the classical type of water, $\mathrm{MLD}_{\mathrm{T} 5}$, and $\mathrm{MLD}_{\theta \mathrm{G}}$ may also be used. The intra-annual variations in $\mathrm{MLD}_{\mathrm{T} 8}$ at the study site followed a well-defined pattern. MLD $_{\mathrm{T} 8}$ was the deepest, $\sim 80 \mathrm{~m}$, in December/January during the northeast monsoon. It was shallower, $\sim 40 \mathrm{~m}$, in June through October during the southwest monsoon. It was the shallowest in May, $\sim 25 \mathrm{~m}$, in the inter-monsoonal period when the wind is the weakest. Diurnal variations in MLD were a common occurrence. However, the variations fell within a relatively well defined range. The standard deviation from the average was $\sim \pm 4 \mathrm{~m}$. MLD estimations from once through profiling would include this inherent uncertainty and this effect can be significant when the MLD is shallow.

Acknowledgements George T. F. Wong shared equally correspondence in the preparation of this manuscript. The authors thank all of the chief scientists for leading and collecting the data and giving us permission to use the data from these cruises, the Ocean Data Bank of the Ministry of Science and Technology, Taiwan at the Institute of Oceanography of the National Taiwan University for making the data available for this study. The assistance of the captains and crews of R/V-OR1 and OR3 in the cruises is greatly appreciated. We also thank the Earth System Research Lab of NOAA for making the remotely sensed SST and wind speeds data available in their web site. This work was supported in part by the Ministry of Science and Technology through grants NSC 101-2611-M-001-003-MY3 and by the Academia Sinica through a thematic project grant titled "Ocean Acidification: Comparative biogeochemistry in shallow-water tropical coral reef ecosystems in a naturally acidic marine environment". This manuscript was completed while Wong was supported as a visiting professor at the University of Malaya.

\section{REFERENCES}

Brainerd, K. E. and M. C. Gregg, 1995: Surface mixed and mixing layer depths. Deep-Sea Res. Part I-Oceanogr. Res. Pap., 42, 1521-1543, doi: 10.1016/09670637(95)00068-H. [Link]

Dong, S., J. Sprintall, S. T. Gille, and L. Talley, 2008: Southern Ocean mixed-layer depth from Argo float profiles. J. Geophys. Res., 113, C06013, doi: 10.1029/2006JC004051. [Link]

Ducklow, H. W., D. K. Steinberg, and K. O. Buesseler, 2001: Upper ocean carbon export and the biological pump. Oceanography, 14, 50-58, doi: 10.5670/oceanog.2001.06. [Link]

Ge, R. F., F. L. Qiao, F. Yu, Z. X. Jiang, and J. S. Guo, 2003: A method for calculating thermocline characteristic elements in shelf sea area-Quasi-step function approximation method. Adv. Mar. Sci., 1, 35-39. (in Chinese)

Hao, J., Y. Chen, F. Wang, and P. Lin, 2012: Seasonal thermocline in the China Seas and northwestern Pacific Ocean. J. Geophys. Res., 117, C02022, doi: 10.1029/2011JC007246. [Link]

Huang, R. X. and S. Russell, 1994: Ventilation of the 
subtropical North Pacific. J. Phys. Oceanogr., 24, 2589-2605, doi: 10.1175/1520-0485(1994)024<2589: VOTSNP $>2.0 . C O ; 2$. [Link]

Kara, A.B.,P. A. Rochford, and H.E.Hurburt, 2000: An optimal definition for ocean mixed layer depth. J. Geophys. Res., 105, 16803-16821, doi: 10.1029/2000JC900072. [Link]

Kelly, K. A. and B. Qiu, 1995: Heat flux estimates for the western North Atlantic. Part I: Assimilation of satellite data into a mixed layer model. J. Phys. Oceanogr., 25, 2344-2360, doi: 10.1175/1520-0485(1995)025<2344: HFEFTW > 2.0.CO;2. [Link]

Lamb, P. J., 1984: On the mixed layer climatology of the north and tropical Atlantic. Tellus A, 36, 292-305.

Levitus, S., 1982: Climatological Atlas of the World Ocean, NOAA Professional Paper, No. 13, U. S. Dept. Commerce, National Oceanic and Atmospheric Administration, Washington, D.C., 173 pp.

Lewis, M. R., M. E. Carr, G. C. Feldman, W. Esaias, and C. McClain, 1990: Influence of penetrating solar radiation on the heat budget of the equatorial Pacific Ocean. Nature, 347, 543-544, doi: 10.1038/347543a0. [Link]

Liu, A. K. and M. K. Hsu, 2004: Internal waves study in the South China Sea using Synthetic Aperture Radar (SAR). Int. J. Remote Sens., 25, 1261-1264, doi: 10.1080/01431160310001592148. [Link]

Liu, A. K., Y. S. Chang, M. K. Hsu, and N. K. Liang, 1998: Evolution of nonlinear internal waves in the East and South China Seas. J. Geophys. Res., 103, 7995-8008, doi: 10.1029/97JC01918. [Link]

Lukas, R. and E. Lindstrom, 1991: The mixed layer of the western equatorial Pacific Ocean. J. Geophy. Res., 96, 3343-3357, doi: 10.1029/90JC01951. [Link]

Maier-Reimer, E. and K. Hasselmann, 1987: Transport and storage of $\mathrm{CO}_{2}$ in the ocean-An inorganic ocean-circulation carbon cycle model. Clim. Dyn., 2, 63-90, doi: 10.1007/BF01054491. [Link]

Miller, J.R., 1976: The salinity effect in a mixed layer ocean model. J. Phys. Oceanogr., 6, 29-35, doi: 10.1175/152 0-0485(1976)006<0029:TSEIAM >2 .0.CO;2. [Link]

Montégut, C. D. B., G. Madec, A. S. Fischer, A. Lazar, and D. Ludicone, 2004: Mixed layer depth over the global ocean: An examination of profile data and a profilebased climatology.J. Geophys. Res., 109, C12003, doi: 10.1029/2004JC002378. [Link]

Monterey, G. I. and S. Levitus, 1997: Seasonal Variability of Mixed Layer Depth for the World Ocean, NOAA atlas Nesdis, Vol. 14, U. S. Dept. of Commerce, National Oceanic and Atmosphereric Administration, Washington, D.C., 100 pp.

Obata, A., J. Ishizaka, and M. Endoh, 1996: Global verification of critical depth theory for phytoplankton bloom with climatological in situ temperature and satellite ocean color data. J. Geophys. Res., 101, 20657-20667, doi: 10.1029/96JC01734. [Link]

Pan, X., G. T. F. Wong, J. H. Tai, and T. Y. Ho, 2015: Climatological of physical and biological characteristics of the northern South China Sea Shelf-sea (NoSoCS) and adjacent waters: Observations from satellite remote sensing. Deep-Sea Res. Part II-Top. Stud. Oceanogr., 117,10-22, doi: 10.1016/j.dsr2.2015.02.022. [Link]

Price, J. F., R. A. Weller, and R. Pinkel, 1986: Diurnal cycling: Observations and models of the upper ocean response diurnal heating, cooling, and wind mixing. J. Geophys. Res., 91, 8411-8427, doi: 10.1029/ JC091iC07p08411. [Link]

Qu, T., 2001: Role of ocean dynamics in determining the mean seasonal cycle of the South China Sea surface temperature. J. Geophys. Res., 106, 6943-6955, doi: 10.1029/2000JC000479. [Link]

Qu, T., H. Mitsudera, and T. Yamagata, 2000: Intrusion of the North Pacific waters into the South China Sea. J. Geophys. Res., 105, 6415-6424, doi: 10.1029/1999JC900323. [Link]

Qu, T., Y. Du, J. Gan, and D. Wang, 2007: Mean seasonal cycle of isothermal depth in the South China Sea. J. Geophys. Res., 112, C02020, doi: 10.1029/2006JC003583. [Link]

Ramp, S. R., T. Y. Tang, T. F. Duda, J. F. Lynch, A. K. Liu, C. S. Chiu, F. L Bahr, K. R. Kim, and Y. J. Yang, 2004: Internal solitons in the northeastern South China Sea: part I. Sources and deep water propagation. IEEE J. Ocean. Eng., 29, 1157-1181, doi: 10.1109/ JOE.2004.840839. [Link]

Sabine, C. L. and T. Tanhua, 2010: Estimation of anthropogenic $\mathrm{CO} 2$ inventories in the ocean. Annu. Rev. Mar. Sci., 2, 175-198, doi: 10.1146/annurev-marine-120308-080947. [Link]

Shaw, P. T., 1989: The intrusion of water masses into the sea southwest of Taiwan. J. Geophys. Res., 94, 1821318226, doi: 10.1029/JC094iC12p18213. [Link]

Shaw, P. T., 1991: The seasonal variation of the intrusion of the Philippine seawater into the South China Sea. $J$. Geophys. Res., 96, 821-827, doi: 10.1029/90JC02367. [Link]

Spall, M. A., 1991: A diagnostic study of the wind- and buoyancy-driven North Atlantic circulation. J. Geophys. Res., 96, 18509-18518, doi: 10.1029/91JC01957. [Link]

Sprintall, J. and M. Tomczak, 1992: Evidence of the barrier layer in the surface layer of the tropics. J. Geophys. Res., 97, 7305-7316, doi: 10.1029/92JC00407. [Link]

Sprintall, J., A. L. Gordon, P. Flament, and C. L. Villanoy, 2012: Observations of exchange between the South China Sea and the Sulu Sea. J. Geophys. Res., 117, C05036, doi: 10.1029/2011JC007610. [Link]

Thompson, R. O. R. Y., 1976: Climatological models of the surface mixed layer of the ocean. J. Phys. Oceanogr., 
6, 496-503, doi: 10.1175/1520-0485(1976)006<0496: CNMOTS $>2.0 . C O ; 2$. [Link]

Tseng, C. M., G. T. F. Wong, I. I. Lin, C. R. Wu, and K. K. Liu, 2005: A unique seasonal pattern in phytoplankton biomass in low-latitude waters in the South China Sea. Geophys. Res. Lett., 32, L08608, doi: 10.1029/2004GL022111. [Link]

Tseng, C. M., G. T. F. Wong, W. C. Chou, B. S. Lee, D. D. Sheu, and K. K. Liu, 2007: Temporal variations in the carbonate system in the upper layer at the SEATS station. Deep-Sea Res. Part II-Top. Stud. Oceanogr., 54, 1448-1468, doi: 10.1016/j.dsr2.2007.05.003. [Link]

Tseng, C. M., G. C. Gong, L. W. Wang, K. K. Liu, and Y. Yang, 2009: Anomalous biogeochemical conditions in the northern South China Sea during the El-Niño events between 1997 and 2003. Geophys. Res. Lett., 36, L14611, doi: 10.1029/2009GL038252. [Link]

Wagner, R. G., 1996: Decadal scale trends in mechanisms controlling merdional sea surface temperature gradients in the tropical Atlantic. J. Geophys. Res., 101, 16683-16694, doi: 10.1029/96JC01214. [Link]

Wong, G. T. F., C. M. Tseng, L. S. Wen, and S. W. Chung, 2007a: Nutrient dynamics and N-anomaly at the SEATS station. Deep-Sea Res. Part II-Top. Stud. Oceanogr., 54, 1528-1545, doi: 10.1016/j.dsr2.2007.05.011. [Link]

Wong, G. T. F., T. L. Ku, M. Mulholland, C. M. Tseng, and D. P. Wang, 2007b: The South East Asian time-series study (SEATS) and the biogeochemistry of the South China Sea. Deep-Sea Res. Part II-Top. Stud. Oceanogr., 54, 1434-1437, doi: 10.1016/j.dsr2.2007.05.012. [Link]

Zawada, D. G., J. R. V. Zaneveld, E. Boss, W. D. Gardner, M. J. Richardson, and A. V. Mishonov, 2005: A comparison of hydrographically and optically derived mixed layer depths. J. Geophys. Res., 110, C11001, doi: 10.1029/2004JC002417. [Link]

Zhang, H. M., J. J. Bates, and R. W. Reynolds, 2006: Assessment of composite global sampling: Sea surface wind speed. Geophys. Res. Lett., 33, L17714, doi: 10.1029/2006GL027086. [Link]

Zhao, Z., V. Klemas, Q. Zheng, and X. H. Yan, 2004: Remote sensing evidence for baroclinic tide origin of internal solitary waves in the northeastern South China Sea. Geophys. Res. Lett., 31, L06302, doi: 10.1029/2003GL019077. [Link] 